Jurnal Teknik Komputer AMIK BSI

Volume 7, No.1, Januari 2021

P-ISSN 2442-2436, E-ISSN: 2550-0120

Akreditasi Ristekdikti, No: 36/E/KPT/2019 (Sinta 4)

DOI: $10.31294 /$ jtk.v4i2

\title{
Perangkingan Rekomendasi Supplier Terbaik menggunakan Metode AHP dan Promethee
}

\author{
Marlina $^{1}$, Wina Yusnaeni ${ }^{2}$ \\ ${ }^{1,2}$ Universitas Bina Sarana Informatika \\ ${ }^{1}$ marlina.mln@bsi.ac.i.id \\ ²wina.wyi@bsi.ac.id

\begin{tabular}{ccc}
\hline Diterima & Direvisi & Disetujui \\
$28-09-2020$ & $04-10-2020$ & $01-03-2020$ \\
\hline
\end{tabular}

\begin{abstract}
Abstrak - Dalam dunia perindustrian tentunya ketelitian dalam memilih bahan produksi adalah hal utama. Bahan produksi dipilih bukan hanya dari sisi kualitas bahan itu sendiri namun dari sisi pemilihan supplier yang tepat juga menentukan produksi yang baik. Dengan pemilihan yang tepat maka diperlukann kehati hatian. Oleh karena itu pemilihan pemilihan dilakukan dengan menggunakan beberapa aspek diantaranya harga, mutu barang, pengiriman, cara pembayaran, pelayanan dan aspek K3L. Untuk mengolah data tersebut supaya mendapatkan perangkingan yang akurat yaitu dengan menggunakan AHP (Analytical Hierarchy Process) dan Promethee (Preference Ranking Organization METHod for Enrichment Evaluation). Dengan kedua metode tersebut maka akan didapatkan perangkingan supplier dari yang paling rendah sampai yang tertinggi. Dengan mendapatkan hasil perangkingan ersebut tentunya akan memudahkan pimpinan dalam hal ini adalah manajer untuk meilih supplier terbaik. Dengan terpilihnya supplier terbaik tentunya proses produksi akan berjalan lancar dan dan barang yang dihasilpun memiliki kwalitas terbaik. Dengan menghasilkan produk yang berkwalitas tentunya akan mempengaruhi hasil penjualan nanti dan itu sangat menguntungkan perusahaan.
\end{abstract}

Kata Kunci: Supplier, Perangkingan, kriteria

\begin{abstract}
In the industrial world, of course, accuracy in choosing production materials is the main thing. Production materials are chosen not only in terms of the quality of the materials themselves, but in terms of choosing the right supplier also determines good production. With the right selection, caution is needed. Therefore, the selection of the selection is done by using several aspects including price, quality of goods, delivery, payment methods, services and aspects of K3L. To process the data in order to obtain an accurate ranking, namely by using AHP (Analytical Hierarchy Process) and Promethee (Preference Ranking Organization METHod for Enrichment Evaluation). With these two methods, the supplier ranking will be obtained from the lowest to the highest. By getting the ranking results, it will certainly make it easier for the leader, in this case, the manager to choose the best supplier. With the selection of the best supplier, of course, the production process will run smoothly and the goods produced will have the best quality. By producing quality products, it will certainly affect the sales results later and it will greatly benefit the company.
\end{abstract}

Keywords: supplier,rangkings, criteria

\section{PENDAHULUAN}

Mengapa dibutuhkan pemilihan supplier karena untuk rantai pasokan bahan industri. Jika bahanbahan yang dipiih dr supplier yang terbaik otomatis pemasokan akan lancar serta barang yang dikirim di dapat dari harga yang terbaik serta kualitas yang bagus. Hal itu juga yang sangat diperhatikan oleh perusahan yang bergerak dibidang produksi alat-alat pabrik. Supplier yang tepat sangatlah menentukan atas kesiapan pasokan bahan baku, pentingnya peranan supplier dalam penyediaan bahan baku merupakan salah satu syarat dalam kelancaran suatu produksi (Yusnaeni \& Ningsih, 2019), sehingga produksi akan tetep bejalan dan pemintaan konsumen akan terpenuhi. Biasanya supplier mempunyai kinerja yang baik dalam satu kriteria saja padahal perusahaan mnginginkan performa yang baik yang memnuhi nilai kriteria yang ditargetkan oleh perusahaan (R. Wulandari, 2017). Kelemahan dalam Penilaian untuk pendukung keputusan yang hanya berdasarkan harga yang ditawarkan dan kualitas dianggap sebagai penilaian yang bersifat subjektif (N. Wulandari, 2014) Pemilihan suppier tebaik bukanlah hal yang mudah dilakukan oleh suatu peusahaan. Banyak kriteria 
yang perlu diperhatikan, seperti kualitas yang baik, pengiriman tepat waktu sampai dengan kapasitas produksi yang memadai (Rimantho, Fathurohman, Cahyadi, \& Sodikun, 2017). Karena ada banyak syarat yang harus di penuhi. Perangkingan ini dilakukan sebagai salah satu cara untuk memudahkan seorang manajer menentukan kemana pembelian barang-barang kebutuhan produksi bermuara.

Dalam pemilihan ini bisa menggunakan beberapa kriteria yang telah ditentukan oleh pihak perusahaan yaitu yang pertama adalah harga. Harga disini tentunya mengenai apakah harga yang diberikan supplier bisa menekkan budget produksi. Yang kedua adalah mutu barang, sebagaimana harga mutu barang juga sangat penting. Jika ada suplier yang memberikan harga yang rendah namun mutu barang yang diberikan kurang bagus juga tidak dapat dipilih. Selanjutnya yang ketigga adalah pengiriman. Pengiriman disini menyangkut apakah mengiriman barang yang diminta oleh perusahaan akan tepat waktu karena keterlambatan pengiriman barang maka akan menghambat produksi di perusahaan. Yang keempat adalah cara pembayaran yang disediakan apakah bisa secara kredit atau harus tunai semua. Selain itu yang kelima adalah pelayanan, dimana pelayanan yang baik dari supplier akan membuat perusahaan nyaman untuk melakukan pembelian barang. Yang terakhir adalah aspek K3L (Kesehatan, Keamanan, eselamatan dan Lingkungan). Aspek K3L ini merupakan aspek penting yang merupakan dasar komitmen dari supplier.

Dalam menentukan perangkingan supplier terbaik pada perusahaan dapat digunakan metode AHP (Analytical Hierarchy Process) yang digunakan dalam penentuan konsistensi bobot kriteria yang digunakan dan Promethee (Preference Ranking Organization Method for Enrichment Evaluation) yang digunakan sebagai pengolahan data dalam penentuan perangkingan supplier.

Dipilihnya metode promethee karena mudah dalam penggunaan aplikasinya, tingkat efisiensinya, dan inter-aktivitas (Taufik, Syaripudin, \& Jumadi, 2017). Diharapkan dengan menggunakan metode Promethee dalam pendukung keputusan rekomendasi ternbaik untuk supplier bersifat multiobjektive dan juga multikriteria (Ayu, Tanuwijaya, Jurusan, Informasi, \& Surabaya, 2009). Hasil dari perhitungan dengan menggunakan metode AHP dan Promethee adalah perangkingan rekomendasi supplier terbaik yang nantinya akan menentukan keberlanjutan kerjasama pemesanan bahan baku terhadap supplier.

\section{METODOLOGI PENELITIAN}

\section{Diagram Penelitian}

Alur Penelitian untuk menentukan rekomendasi supplier terbaik di jelaskan dalam diagram dibawah ini:

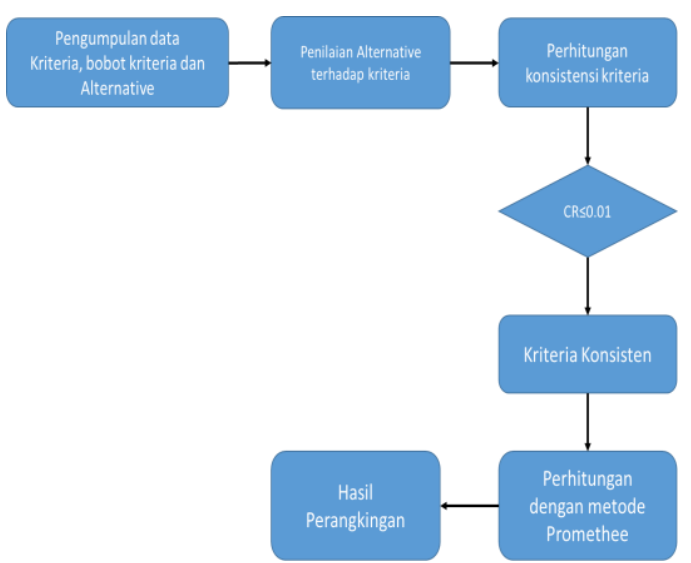

Gambar 1. Diagram Penelitian

Tahap awal dilakukan dengan pengumpulan data , pada tahap ini dilakukan penentuan kriteria dan bobot yang digunakan dalam penilaian. Selain itu data alternative yang dinilai dalam studi kasus ini adalah supplier berjumlah 10 supplier serta penilai yang merupakan adalah penentu keputusan di dalam perusahaan seperti manager, supervisor dll. Tahap berikutnya dilakukan penilaian yang dilakukan oleh penentu keputusan untuk menilai alternative terhadap kriteria.tahapa ketiga adalah perhitungan untuk bobot kriteria dengan menggunakan metode ahp untuk mengetahui konsistensi kriteria, jika mememnuhi ketentuan yaitu $\mathrm{CR}<=0,1$ maka kriteria dikatakan konsisten dan bisa digunakan, jika tidak maka dilakukan perhitungan ulang terhadap kriteria. Tahap keempat dilakukan perhitunan denga menggunakan metode promethee untuk penentuan perangkingan rekomendasi terbaik terhadap supplier.

\section{Kriteria}

Kriteria yang digunakan terdiri dari enam kriteria dengan nilai range masing-masing kriteria 1-3. Dimana range harga dinilai dari harga mahal murah, mutu barang, pelayanan, dan aspek K3L dilihat dari cukup baik hingga baik, sedangkan cara pembayaran dilihat dari segi kredit dan tunai.

Tabel 1. Tabel Kriteria yang digunakan Kriteria

\begin{tabular}{ll}
\hline F1 & Harga (Biaya subkon) \\
\hline F2 & Mutu Barang/ Hasil Pekerjaan \\
\hline F3 & $\begin{array}{l}\text { Tepat Waktu Pengiriman barang / pelaksanaan } \\
\text { pekerjaan }\end{array}$ \\
\hline F4 & Cara Pembayaran \\
\hline F5 & Pelayanan Yang Baik/ Tngkah Laku \\
\hline F6 & Aspek K3L \\
\hline
\end{tabular}

\section{AHP}

Metode AHP pertama kali di diperkenalkan oleh L. Saaty tahun 1970 (Munthafa \& Mubarok, 2017). AHP merupakan metode yang digunakan untuk menyelesaikan masalah multikriteria dengan bentuk hierarki (Kristiyanti, Sugiharto, \& Wibawa, 2013). Di dalam metode AHP ada tiga prinsip yang 
digunakan yaitu decomposition, comparative judgement, dan logical consistency (Kristiyanti et al., 2013).

\section{Promethee}

Promethee salah satu metode sistem pendukung keputusan yang ciptakan pertama kali tahun 1982, dimana penentuan urutan prioritas dengan multikriteria (Pami, 2017). Terdapat tiga prinsip dari metode promethee yaitu(Diana, S.Si, 2018):

a) Gagasan kriteria

Dengan Struktur preference $\{\mathrm{I}, \mathrm{P}\}$. Dimana a $\mathrm{P}$ $b$ jika hanya $f(a)>f(b)$. a I b jika dan hanya jika $f(a)=f(b)$.

b) nilai relasi outranking yaitu pertimbangan nilai relasi untuk menyelesaikan masalah dalam penentuan keputusan perangkingan terutama untuk relasi yang kurang sensitif terhadap perubahan kecil.

c) Pandayagunaan outrangking dimana dilakukan pengurutan dari yang terbaik hingga terburuk. Pada metode promethee I diberikan peringkat parsial dan pada metode Promethee II diberikan peringkat lengkap.

\section{Relevansi penelitian}

Beberapa penelitian yang relevansi menggunakan metode promethee diantaranya : penelitian dalam pemilihan lokasi pembangunan pengisian bahan bakar dengan hasil peringkat lokasi yang paling sesuai sebagai lokasi pembangunan pengisian bahan bakar (Yudha, Yuwono, \& Kodong, 2015), penelitian seleksi penerimaan calon karyawan yang menghasilkan dibangunnya suatu aplikasi menggunakan metode promethee dalam perangkingan calon karyawan (Azizah \& Winiarti, 2014), serta penelitian penentuan beasiswa yang menghasilkan Hasil perhitungan yang berjumlah 80 data pengujian dengan metode Promethee didapatkan tingkat Akurasi $=72,5 \%$ dan Presisi $=$ $78 \%$ (Hikmah, Arifianto, \& Suharso, 2005).

\section{HASIL DAN PEMBAHASAN}

Menghitung konsistensi kriteria dengan AHP

Dilakukan dengan kriteria yang telah di tentukan kemudia dilakukan melalui tahapan AHP (Teddy Setiady, Damdam Damiyana2, 2018) dimulai dari:

1. Membuat kriteria dalam kolom matrik berpasangan.

2. Menjumlahkan matriks kolom.

Tabel 1. Penjumlahan matrik kolom

\begin{tabular}{|l|c|c|c|c|c|c|}
\hline & F1 & F2 & F3 & F4 & F5 & F6 \\
\hline F1 & 1,00 & 0,33 & 0,33 & 0,33 & 0,20 & 0,20 \\
\hline F2 & 3,00 & 1,00 & 3,00 & 2,00 & 0,33 & 0,20 \\
\hline F3 & 3,00 & 0,33 & 1,00 & 3,00 & 0,33 & 0,20 \\
\hline F4 & 3,00 & 0,50 & 0,33 & 1,00 & 0,33 & 0,33 \\
\hline F5 & 5,00 & 3,00 & 3,00 & 3,00 & 1,00 & 0,33 \\
\hline F6 & 5,00 & 5,00 & 5,00 & 3,00 & 3,00 & 1,00 \\
\hline $\begin{array}{l}\text { Jumla } \\
\text { h }\end{array}$ & 20,00 & 10,17 & 12,67 & 12,33 & 5,20 & 2,27 \\
\hline \multicolumn{7}{|l|}{} \\
\hline
\end{tabular}

3. Menghitung nilai elemen masing dan dibagi dengan jumlah matrik kolom.

Tabel 2. Nilai elemen

\begin{tabular}{|r|r|r|r|r|r|r|}
\hline & 0,05 & 0,0327 & 0,0263 & 0,0270 & 0,0384 & 0,0882 \\
& & 87 & 16 & 27 & 62 & 35 \\
\hline & 0,15 & 0,0983 & 0,2368 & 0,1621 & 0,0641 & 0,0882 \\
& & 61 & 42 & 62 & 03 & 35 \\
\hline & 0,15 & 0,0327 & 0,0789 & 0,2432 & 0,0641 & 0,0882 \\
& & 87 & 47 & 43 & 03 & 35 \\
\hline $\mathrm{N}=$ & 0,15 & 0,0491 & 0,0263 & 0,0810 & 0,0641 & 0,1470 \\
& & 8 & 16 & 81 & 03 & 59 \\
\hline & 0,25 & 0,2950 & 0,2368 & 0,2432 & 0,1923 & 0,1470 \\
& & 82 & 42 & 43 & 08 & 59 \\
\hline & 0,25 & 0,4918 & 0,3947 & 0,2432 & 0,5769 & 0,4411 \\
& & 03 & 37 & 43 & 23 & 76 \\
\hline
\end{tabular}

4. Menghitung nilai prioritas dengan rumus selanjutnya menjumlahkan matrik baris dan hasilnya dibagi dengan jumlah kriteria.

Tabel 3. Nilai Prioritas setiap Kriteria

\begin{tabular}{|r|}
\hline \multicolumn{1}{|l}{ Proritas } \\
\hline 0,043804 \\
\hline 0,133284 \\
\hline 0,109553 \\
\hline 0,08629 \\
\hline 0,227422 \\
\hline 0,399647 \\
\hline
\end{tabular}

5. Menguji nilai konsistensi matrik berpasangan dengan rumus.

Tabel 4 Mengukur Konsistensi:

\begin{tabular}{|c|c|r|r|r|r|r|}
\hline & 0,043 & 0,044 & 0,036 & 0,028 & 0,045 & 0,079 \\
804 & 428 & 518 & 763 & 484 & 929 \\
\hline 0,131 & 0,133 & 0,328 & 0,172 & 0,075 & 0,079 \\
413 & 284 & 658 & 58 & 807 & 929 \\
\hline 0,131 & 0,044 & 0,109 & 0,258 & 0,075 & 0,079 \\
$\mathbf{K}$ & 413 & 428 & 553 & 869 & 807 & 929 \\
\cline { 2 - 7 } & 0,131 & 0,066 & 0,036 & 0,086 & 0,075 & 0,133 \\
413 & 642 & 518 & 29 & 807 & 216 \\
\hline 0,219 & 0,399 & 0,328 & 0,258 & 0,227 & 0,133 \\
022 & 851 & 658 & 869 & 422 & 216 \\
\hline 0,219 & 0,666 & 0,547 & 0,258 & 0,682 & 0,399 \\
& 22 & 419 & 763 & 869 & 267 & 647 \\
\hline
\end{tabular}

Dari tahapan diatas di dapat nilai $\Lambda=6,60743$, $\mathrm{CI}=0,121486$, dan hasil nilai konsistensi sebesar CR = 0,097972539, berdasarkan hasil tersebut didapat $\mathrm{CR}<=0.01$ dengan hasil $\mathrm{CR}$ yang kurang dari 0,01 maka kriteria yang digunakan dianggap konsisten dan dapat digunakan dalam pengolahan data selanjutnya.

Dari penilaian kriteria terhadap alternative di dapat data sebagai berikut:

Tabel 5. Penilaian Kriteria terhadap alternative

\begin{tabular}{|c|c|c|c|c|c|c|}
\hline Kode & K1 & K2 & K3 & K4 & K5 & K6 \\
\hline S1 & 2 & 2 & 3 & 2 & 2 & 2 \\
\hline S2 & 1 & 2 & 3 & 2 & 2 & 2 \\
\hline S3 & 2 & 2 & 2 & 1 & 3 & 2 \\
\hline S4 & 2 & 2 & 2 & 1 & 3 & 2 \\
\hline S5 & 2 & 1 & 2 & 1 & 2 & 1 \\
\hline
\end{tabular}




\begin{tabular}{|c|l|l|l|l|l|l|}
\hline S6 & 2 & 2 & 2 & 1 & 2 & 2 \\
\hline S7 & 2 & 1 & 2 & 2 & 2 & 2 \\
\hline S8 & 3 & 3 & 3 & 2 & 3 & 3 \\
\hline S9 & 2 & 2 & 3 & 1 & 3 & 3 \\
\hline S10 & 2 & 3 & 3 & 2 & 3 & 2 \\
\hline
\end{tabular}

Pengolahan data dengan menggunkan metode Promethee Tahapan dalam Perhitungan Promethee (Ayu et al., 2009):

1. Menentukan deviasi berdasarkan perbandingan berpasangan dengan rumus:

$$
d_{j}(a, b)=f(a)-f(b), j=1,2, \ldots \ldots \ldots m \ldots \ldots . .(1)
$$

jumlah perbadingan berpasangan dan didapat dari 10 supplier dengan label $\{\mathrm{S} 1, \mathrm{~S} 2, \ldots . . \mathrm{S} 10\}$, sehingga di dapat nilai 90 perbandingan berpasangan.penentuan deviasi menggunakan rumus:

$\mathrm{d}(\mathrm{S} 1, \mathrm{~S} 2) \mathrm{F} 1=\mathrm{S} 1-\mathrm{S} 2=2-1=1$

$\mathrm{d}(\mathrm{S} 2, \mathrm{~S} 1) \mathrm{F} 1=\mathrm{S} 2-\mathrm{S} 1=1-2=-1$

$\mathrm{d}(\mathrm{S} 1, \mathrm{~S} 3) \mathrm{F} 1=\mathrm{S} 1-\mathrm{S} 3=2-2=0$

$\mathrm{d}(\mathrm{S} 3, \mathrm{~S} 1) \mathrm{F} 1=\mathrm{S} 3-\mathrm{S} 1=2-2=0$

Dst...

2. Menghitung fungsi preferensi

$p_{j}(a, b)=f_{j}\left(d_{j}(a, b), j=1,2,3, \ldots \ldots \ldots m\right.$

Dengan ketentuan $d \leq 0$ maka $p(d)=0$, jika $d>0$ maka $\mathrm{p}(\mathrm{d})=1$, didapat dalam bentuk tabel di bawah:

Tabel 6. Penerapan Fungsi preferensi biasa

\begin{tabular}{|c|c|c|c|c|c|c|c|}
\hline \multicolumn{2}{|c|}{ Perbandingan } & F1 & F2 & F3 & F4 & F5 & F6 \\
\hline S1 & S2 & 0 & 0 & 0 & 0 & 0 & 0 \\
\hline S2 & S1 & 0 & 0 & 0 & 0 & 0 & 0 \\
\hline S1 & S3 & 0 & 0 & 1 & 1 & 0 & 0 \\
\hline S3 & S1 & 0 & 0 & 0 & 0 & 1 & 0 \\
\hline S10 & S9 & 0 & 1 & 0 & 1 & 0 & 0 \\
\hline
\end{tabular}

3. Perhitungan indeks preferensi global

$$
\varphi(a, b)=\sum_{i=1}^{n} p_{j}(a, b) * w_{j}, \forall a, b \in A
$$

$\varphi(a, b)$ merupakan insenitas preferensi pembuat keputusan yang menyatakan bahwa alternatif a lebih baik daripada alternatif $b$ dengan pertimbangan secara simultan dari seluruh kriteria. Perhitungan indeks preferensi global dengan nilai bobot dengan perhitungan AHP.

\section{Tabel 7. Tabel bobot kriteria}

\begin{tabular}{lcccccc|}
$\begin{array}{l}\text { Krit } \\
\text { eria }\end{array}$ & K1 & K2 & K3 & K4 & K5 & K6 \\
\hline Bobo & $\mathbf{0 , 0 4 3}$ & $\mathbf{0 , 1 3 3}$ & $\mathbf{0 , 1 0 9}$ & $\mathbf{0 , 0 8}$ & $\mathbf{0 , 2 2 7}$ & $\mathbf{0 , 3 9 9}$ \\
\hline
\end{tabular}

$\begin{array}{lllllll}t & 804 & 284 & 553 & 629 & 422 & 647\end{array}$

Yang selanjutnya dilakukan perhitungan dengan rumus sehingga dihasilkan dalam bentuk perbandingan berpasangan:
Tabel 8 .Indeks Preferensi global Perbandingan Berpasangan

\begin{tabular}{ccccccc}
\hline Hasil & S1 & S2 & S3 & S4 & S5 & S10 \\
\hline S1 & 0 & 0,00 & 0,20 & 0,20 & 0,73 & 0,00 \\
\hline S2 & 0,00 & 0 & 0,20 & 0,20 & 0,73 & 0,00 \\
\hline S3 & 0,23 & 0,27 & 0 & 0,00 & 0,76 & 0,00 \\
\hline S4 & 0,23 & 0,27 & 0,00 & 0 & 0,76 & 0,00 \\
\hline S5 & 0,73 & 0,04 & 0,00 & 0,00 & 0 & 0,00 \\
\hline S10 & 0,00 & 0,40 & 0,33 & 0,33 & 0,96 & 0 \\
\hline
\end{tabular}

4. Menghitung aliran perangkingan dan peringkat parsial, Selanjutkan dilakukan perangkingan dan peringkat parsial yang menghasilkan dua jenis hasil yaitu leaving flow dan entering flow untuk menentukan urutan prioritas pada proses metode promethee yang menggunakan urutan parsial.

$$
\begin{aligned}
\Phi^{+}(a) & =\frac{1}{n-1} \sum_{x \in A} \varphi(a, x) \\
\Phi^{-}(a) & =\frac{1}{n-1} \sum_{x \in A} \varphi(x, a)
\end{aligned}
$$

Dimana :

$\Phi^{+}(a)=$ Leaving flow

$\Phi^{-}(a)=$ Entering Flow

Leaving flow dan entering flow untuk menentukan urutan prioritas.

Tabel 9. Tabel Leaving Flow dan Entering Flow

\begin{tabular}{llllll}
\hline & Alternative & $\begin{array}{l}\text { Leaving } \\
\text { Flow }\end{array}$ & & Alternative & $\begin{array}{l}\text { Entering } \\
\text { Flow }\end{array}$ \\
\hline $\boldsymbol{\Phi}^{+}$ & S1 & 0,182825151 & $\phi^{-}$ & S1 & 0,189842925 \\
\hline $\boldsymbol{\Phi}^{+}$ & S2 & 0,182825151 & $\phi^{-}$ & S2 & 0,283712089 \\
\hline $\boldsymbol{\Phi}^{+}$ & S3 & 0,205236744 & $\phi^{-}$ & S3 & 0,232097549 \\
\hline $\boldsymbol{\Phi}^{+}$ & S4 & 0,205236744 & $\phi^{-}$ & S4 & 0,232097549 \\
\hline $\boldsymbol{\Phi}^{+}$ & S5 & 0,085841966 & $\phi^{-}$ & S5 & 0,758135812 \\
\hline $\boldsymbol{\Phi}^{+}$ & S6 & 0,100651277 & $\phi^{-}$ & S6 & 0,358443274 \\
\hline $\boldsymbol{\Phi}^{+}$ & S7 & 0,124192972 & $\phi^{-}$ & S7 & 0,39936038 \\
\hline $\boldsymbol{\Phi}^{+}$ & S & 0,663316984 & $\phi^{-}$ & S 8 & 0 \\
\hline $\boldsymbol{\Phi}^{+}$ & S9 & 0,516849318 & $\phi^{-}$ & S 9 & 0,082424538 \\
\hline $\boldsymbol{\Phi}^{+}$ & S10 & 0,362815443 & $\phi^{-}$ & S10 & 0,093677636 \\
\hline
\end{tabular}

5. Melakukan perhitungan aliran perangkingan bersih dan peringkat lengkap. Hasil dari perangkingan dengan menghitung netflow di dapat dari leaving flow dikurangi entering flow :

$\phi(a)=\phi^{+}(a)-\phi^{-}(a)$

Rumus diatas digunakan untuk menghasilkan keputusan akhirpenentuan urutan atau perangkingan penyelesaian masalah. Hasil perangkingan yang di dapat tergambar pada tabel 10 di bawah ini: 
Tabel 10. Peringkat dengan metode promethee

\begin{tabular}{cc}
\hline Alternative & Perangkingan \\
\hline S8 & $\underline{\mathbf{0 , 6 6 3 3 1 6 9 8 4}}$ \\
\hline S9 & 0,43442478 \\
\hline S10 & 0,269137807 \\
\hline S1 & $-0,007017774$ \\
\hline S3 & $-0,026860805$ \\
\hline S4 & $-0,026860805$ \\
\hline S2 & $-0,100886938$ \\
\hline S6 & $-0,257791997$ \\
\hline S7 & $-0,275167408$ \\
\hline S5 & $-0,672293846$
\end{tabular}

Dilihat dari tabel 10, peringkat dengan nilai tertinggi di hasilkan peringkat yaitu S8 yang memiliki nilai tertinggi yaitu 0,663316984 dan untuk peringkat kedua dan ketika yaitu supplier 9 dan 10 dengan nilai 0,43442478 dan 0,269137807 menjadi rekomendasi supplier terbaik dengan menggunakan metode AHP dan promethee.

\section{KESIMPULAN}

Metode promethee merupakan salah satu jenis DSS atau metode pendukung keputusan yang dapat digunakan untuk penentu keputusan dengan sistem perangkingan. Dengan menggunakan metode AHP untuk perhitungan konsistensi kriteria dengan ketentuan di buktikan kriteria yang digunakan konsisten dengan nilai $\mathrm{CR} \leq 0,01$. Selanjutnya dengan menggunakan perhitungan promethee di dihasilkan perangkingan dengan posisi pertama supplier 8 (S8) dengan nilai 0,663316984 , selanjutnya peringkat kedua dengan nilai 0,43442478 di dapat oleh S9 dst. Kedepannya diharapkan bisa meningkatkan uji perhitungan dengan menggunakan aplikasi sehingga lebih bisa memudahkan pengguna dalam melakukan peenntuan keputusan.

\section{REFERENSI}

Ayu, R., Tanuwijaya, H., Jurusan, /, Informasi, S., \& Surabaya, S. (2009). Penerapan Metode Promethee Dalam Sistem Pendukung Keputusan Pemilihan Supplier Obat Dan Alat Kesehatan (Studi Kasus Pt Mitra Farma Anugerah Lestari Kediri). repository.dinamika.ac.id.

Azizah, N., \& Winiarti, S. (2014). Sistem Pendukung Keputusan Seleksi Calon Karyawan Dengan Metode Promethee Studi Kasus Pamella Group Yogyakarta. Jurnal Sarjana Teknik Informatika, 2(1), 264-278. https://doi.org/10.12928/jstie.v2i1.2633

Diana, S.Si, M. K. (2018). Metode \& Aplikasi Sistem pendukung Keputusan. Yogyakarta: Deeppublish.
Hikmah, H. A., Arifianto, D., \& Suharso, W. (2005). SISTEM PENDUKUNG KEPUTUSAN PENENTUAN PENERIMA BEASISWA MENGGUNAKAN METODE PREFERENCE RANKING ORGANIZATION METHOD FOR ENRICHMENT EVALUATION (PROMETHEE). NASPA Journal, 42(4), 1. https://doi.org/10.1017/CBO9781107415324.0 04

Kristiyanti, L., Sugiharto, A., \& Wibawa, H. A. (2013). Sistem Pendukung Keputusan Pemilihan Pengajar Les Privat Untuk Siswa Lembaga Bimbingan Belajar Dengan Metode Ahp (Studi Kasus Lbb System Cerdas). Jurnal Masyarakat Informatika, 4(7), 39-47. https://doi.org/10.14710/jmasif.4.7.39-47

Munthafa, A., \& Mubarok, H. (2017). Penerapan Metode Analytical Hierarchy Process Dalam Sistem Pendukung Keputusan Penentuan Mahasiswa Berprestasi. Jurnal Siliwangi, 3(2), 192-201.

Pami, S. (2017). Sistem Pendukung Keputusan Pemilihan Karyawan Terbaik Dengan Metode Promethee (Studi Kasus: Pt. Karya Abadi Mandiri). Jurnal Pelita Informatika, 16(3), 298-301.

Rimantho, D., Fathurohman, F., Cahyadi, B., \& Sodikun, S. (2017). Pemilihan Supplier Rubber Parts Dengan Metode Analytical Hierarchy Process Di PT.XYZ. Jurnal Rekayasa Sistem Industri, 6(2), 93. https://doi.org/10.26593/jrsi.v6i2.2094.93-104

Taufik, I., Syaripudin, U., \& Jumadi, J. (2017). Implementasi Metode Promethee Untuk Menentukan Penerima Beasiswa. Jurnal Istek, 10(1).

Teddy Setiady, Damdam Damiyana2, Y. N. (2018). Sistem Pendukung Keputusan Menentukan Karyawan Terbaik Dengan Metode AHP. Sistem Penunjang Keputusan Penilaian Kinerja Karyawan Dalam Pemilihan Karyawan Terbaik Berbasis Web Di LP3I Jakarta, 8.No 1(2088), 119-125.

Wulandari, N. (2014). Perancangan Sistem Pendukung Keputusan Pemilihan Supplier di PT . Alfindo dengan Metode Analytical Hierarchy Process (AHP). Jurnal Sistem Informasi Vol-1, 1(1), 4-7. https://doi.org/24067768

Wulandari, R. (2017). Pemilihan Supplier Bahan Baku Partikel Dengan Metode AHP Dan Promethee. Jurnal Teknik Industri, 16(1), 22. https://doi.org/10.22219/jtiumm.vol16.no1.2230

Yudha, H. A., Yuwono, B., \& Kodong, F. R. (2015). Sistem Pendukung Keputusan Menggunakan 
Metode Promethee (Studi Kasus: Stasiun Pengisian Bahan Bakar Umum). Telematika, 7(1). https://doi.org/10.31315/telematika.v8i1.444 Yusnaeni, W., \& Ningsih, R. (2019). Analisa Perbandingan Metode Topsis, Saw Dan Wp Melalui Uji Sensitifitas Untuk Menentukan Pemilihan Supplier. Jurnal Informatika, 6(1), 9-17. https://doi.org/10.31311/ji.v6i1.4399 